\title{
Web Based Interactive Software In International Business: The Case Of The Global Market Potential System Online $\left(\mathrm{GMPSO}^{\odot}\right)$ \\ Basil J. Janavaras, Minnesota State University, Mankato \\ Emanuel Gomes, Coventry University, U. K. \\ Richard Young, Minnesota State University, Mankato
}

\begin{abstract}
This paper seeks to confirm whether students using the Global Market Potential System Online (GMPSO) web based software, (http://globalmarketpotential.com), for their class project enhanced their knowledge and understanding of international business. The challenge most business instructors and practitioners face is to determine how to bring the real world of business into a classroom or training environment. Experts claim that the answer lies in the Project-Based Learning $(P B L)$ method and web based interactive software widely used at universities and businesses around the world. The findings indicate that the GMPSO enhanced the students' understanding of international business and improved their team working, research and critical thinking skills.
\end{abstract}

Keywords: management, education, international business, strategy, marketing.

\section{INTRODUCTION}

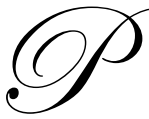

roject-Based Learning is a model that organizes learning around projects. Research projects are complex tasks, based on challenging questions or problems that involve students in design, problemsolving, decision making, or investigative activities. They also provide students with the opportunity to work relatively autonomously over extended periods of time, and culminate in realistic products or presentations (Jones, Rasmussen, and Moffitt, 1997). According to Elayne Shields, PBL incorporates methods from problembased learning, cooperative learning, constructive learning, active learning and project management theory. Developing workplace know-how should be the main objective of any project-based learning. Elayne Shields identifies five competency areas that projects should address: 1) the ability to identify, organize, plan and allocate resources, 2) interpersonal skills, 3) the ability to acquire and use information, 4) the ability to understand complex interrelationships, and 5) the ability to work with a variety of technologies (Shields, 2005).

Interactive learning, made possible with the arrival of the World Wide Web, has a lasting impact on a person's ability to retain and understand information as described by the classic study conducted by the National Training Laboratory's "Learning Pyramid" (DeKanter, 2005). As represented by the statistics on retention rates below, students will have a greater opportunity to learn and retain the information presented in the web based tools than by simply learning the material in a traditional way:

$\begin{array}{lll}- & \text { Teach others/use immediately } & 90 \% \\ - & \text { Practice by doing } & 75 \% \\ - & \text { Discussion Group } & 50 \% \\ \text { - } & \text { See a demonstration } & 30 \%\end{array}$




$\begin{array}{lll}\text { - } & \text { Learn from audio/visual } & 20 \% \\ \text { - } & \text { Reading } & 0 \% \\ & \text { Lecture } & 5 \%\end{array}$

Using web based learning tools is a natural progression for education. Currently four out of five managers under the age of 34 have significant video game experience. With this new "gamer" group also comes a new belief system, which arguably better equips gamers than non-gamers (Beck and Carstens, 2005). Beck and Carstens have shown that games and simulations help to build user's confidence in their own abilities, develop leadership skills and improve self-dependence.

Despite the lack of a universally accepted model or theory of PBL, five criteria should be considered when determining the effectiveness of a model: centrality, driving question, constructive investigations, autonomy, and realism. First, projects must be central to the curriculum and not peripheral; meaning that projects are the curriculum. Second, projects should be designed to force students to encounter and struggle with the central concepts and principles of the discipline. Third, projects should create constructive investigation that involves inquiry, knowledge building, and resolution. Fourth, projects are student-driven and not instructor-lead or scripted. Fifth, projects should be realistic and relate to the real world (Thomas, 2000). According to Elayne Shields, PBL focuses on both the process and product of an assignment, develops the ability to adapt to change, and develops team dynamic and project management skills.

\section{THE GLOBAL MARKET POTENTIAL SYSTEM ONLINE@ (GMPSO)}

The challenge most software designers face, as noted by Kirkley and Kirkley, is to figure out how to bring the real world into the classroom or training environment (making the project realistic). The GMPSO web based software is designed to do exactly that, i.e., bring realism into the classroom. More specifically, the GMPSO enables students to perform a company situation analysis, determine a company's readiness to internationalize and identify the best country markets for the company's products or services (Janavaras, 2006). The software consists of two phases. Phase 1, enables students to perform a situations analysis of a company. Phase 2, provides students with the opportunity to research, select and identify the best country to enter based on market potential using three sets of criteria: Macro, accessibility and micro as shown below.

Phase 1 - Situation Analysis

\begin{tabular}{|c|c|c|c|c|c|c|c|}
\hline 1.1 & 1.2 & 1.3 & 1.4 & 1.5 & 1.6 & 1.7 & Phase 1 \\
\hline Company Analysis & Intl Involvement & Industry Analysis & Target Market Profile & Product Profile & Global Readiness & S.W.O.T. & Report \\
\hline
\end{tabular}

Objective: The objective of Phase 1 is to conduct an in-depth situation analysis of a company by following the procedure below.

- $\quad$ Choose an industry and a company within the industry

- Select:

$\circ \quad$ A specific product line / service of the chosen company (If more than one product lines / services are available).

- If you choose a retail establishment as your company, you need to decide on the merchandise mix to be included in your overseas operation (e.g. Target, McDonald's, Starbucks, Best Buy etc).

- $\quad$ Conduct an internal analysis of the company.

- $\quad$ Determine the international involvement, if any, of the company.

- $\quad$ Conduct a product / market analysis for the company's chosen product(s) or service(s).

- $\quad$ Evaluate the performance of the chosen industry and identify the trends in the industry.

- $\quad$ Determine the company's readiness to do business in the international arena.

- $\quad$ Conduct a S.W.O.T (Strengths, Weaknesses, Opportunities and Threats) analysis of the company. 
- $\quad$ Briefly state your conclusions and recommendations for Phase 1.

- $\quad$ Generate your Phase 1 Report

Phase 2 - Country Selection

\begin{tabular}{|c|c|c|c|c|c|}
\hline 2.1 & 2.2 & 2.3 & 2.4 & Conclusion & \multirow{2}{*}{ Phase 2 Report } \\
\hline $\begin{array}{c}\text { Country } \\
\text { Selection }\end{array}$ & Macro & Market & Micro & Conclusions \& \\
Screening & Accessibility & Recoming & Recommendations & \\
\hline
\end{tabular}

Objective: The objective of Phase 2 is to identify high potential country markets for your company's product(s) or service(s) for the purpose of either exporting or manufacturing products in the selected markets by following the procedure below.

- $\quad$ Research and select a minimum of five (5) and a maximum of ten (10) countries. These are the country markets which you will analyze, score, and rank throughout phase 2

- $\quad$ Select criteria (macro level / market accessibility / micro-level) that are essential in determining high potential country markets for your company's product(s) / service(s).

- Determine the relative importance (weight) of each criterion on a scale of 1-100. Enter the values and rank on a scale of 1-5 relative to the other countries values.

- $\quad$ State your conclusions and recommendations for Phase 2.

- $\quad$ Generate the Phase 2 Report.

\section{METHODOLOGY}

An anonymous survey questionnaire was administered to 116 students enrolled in different sections of the principles of international business course at Minnesota State University, Mankato during spring semester of 2006. The sections were taught by two different instructors. The survey was a Likert Scale, 1 (Strongly Disagree) to 5 (Strongly Agree). The purpose of the survey was to determine: 1. the usability, 2. usefulness, and 3. level of engagement of the GMPSO software. The survey questions are provided in Appendix 1.

Statistical significance is measured utilizing a weighted variance calculated as:

$$
s_{u}^{2}=\frac{\sum_{i=1}^{N} w_{i}\left(x_{i}-\bar{x}_{w}\right)^{2}}{\frac{\left(N^{\prime}-1\right) \sum_{i=1}^{N} w_{i}}{N^{\prime}}} \text { where } N^{\prime} \text { is number of non zero weights. }
$$

Here the weights assigned for a question are the distribution of sample for that question. Let me illustrate for the question "The GMPSO seemed to be laid out logically":

\begin{tabular}{lccccc}
\hline Illustration 1 & & & & \\
\hline & Strongly Disagree & Disagree & Neutral & Agree & Strongly Agree \\
E. The GMPSO seemed to be laid out logically. & 1 & 2 & 3 & 4 & 5 \\
\hline
\end{tabular}


The weights are 2,3,27,64 and 20 for 1,2,3,4,5 respectively. Therefore the weighted mean for our case is given by equation (2):

$$
\bar{x}_{W}=\frac{\sum_{i=1}^{5} w_{i} * x_{i}}{\sum_{i=1}^{5} w_{i}}
$$

Therefore, the weighted mean for the above question, question 5, is calculated as:

$$
\begin{aligned}
& \bar{x}_{E}=\frac{2 * 1+3 * 2+27 * 3+64 * 4+20 * 5}{2+3+27+64+20} \\
& =\frac{445}{116} \\
& =3.836
\end{aligned}
$$

\section{USABILITY OF GMPSO SOFTWARE}

\begin{tabular}{|c|c|c|c|c|}
\hline \multicolumn{5}{|c|}{ Table 1: Usability of GMPSO software } \\
\hline & Weighted Mean & Weighted Variance & Weighted Standard Deviation & Coefficient of Variation (\%) \\
\hline Q1 & 3.655172 & 0.778092 & 0.882095 & 24.13279 \\
\hline Q2 & 3.689655 & 1.109542 & 1.053348 & 28.54869 \\
\hline Q3 & 4.387931 & 1.807868 & 1.34457 & 30.64245 \\
\hline Q4 & 3.801724 & 0.785895 & 0.886507 & 23.31855 \\
\hline Q5 & 3.836207 & 0.837173 & 0.914972 & 23.85094 \\
\hline Q6 & 3.715517 & 1.077958 & 1.038247 & 27.94355 \\
\hline
\end{tabular}

The sample size of 116 students from different areas of study and different classes makes it unbiased sample. The descriptive statistics that I would like to stress upon are weighted mean, weighted standard deviation and coefficient of variation, as shown in the Table 1.

Table 1 demonstrates that the respondents found the GMPSO useful as the mean is above 3 (Neutral) for all the questions asked in relation to the usefulness of the software. Higher weighted standard deviation demonstrates there is high degree of variability around the mean and therefore explaining high coefficient of variation. To explain further, consider the distribution of sample the sample for the questions concerning the usability of software given in Figure 1.

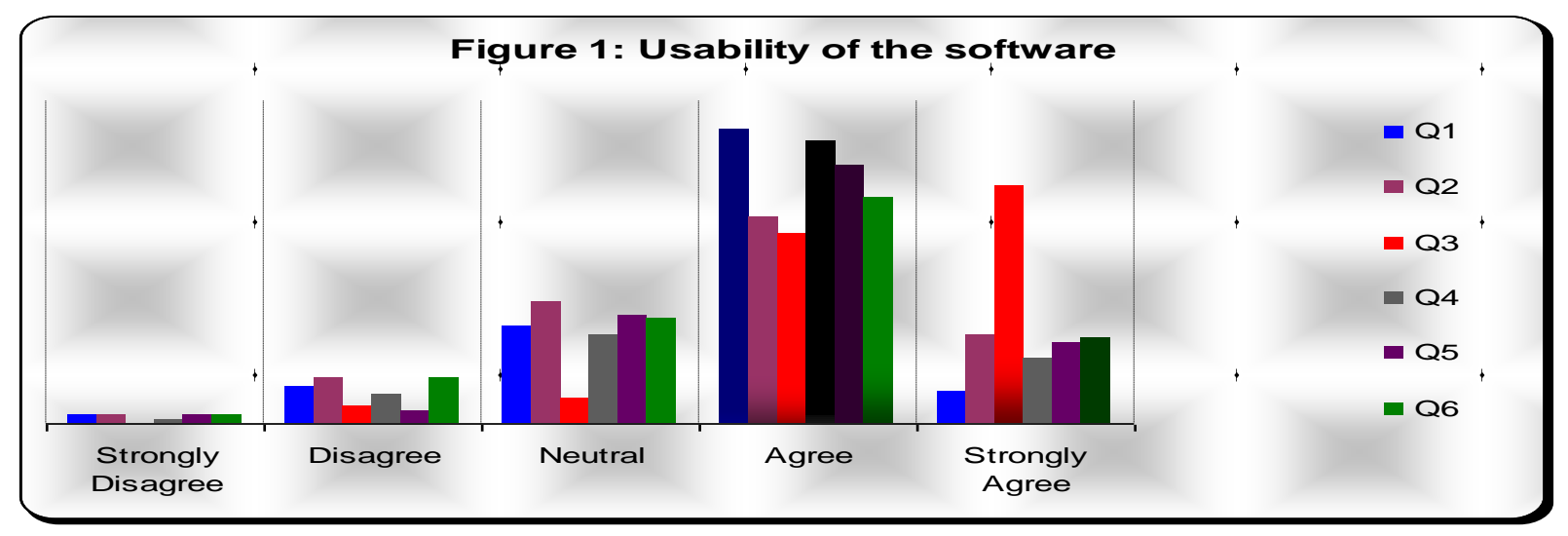


When analyzing Table 1 in conjunction with the descriptive statistics we can safely say that the distribution is positively skewed and therefore the high degree of standard deviation enhances the usability of the software. Figure 2 further demonstrates that the distribution of the survey is positively skewed consider Figure 2.

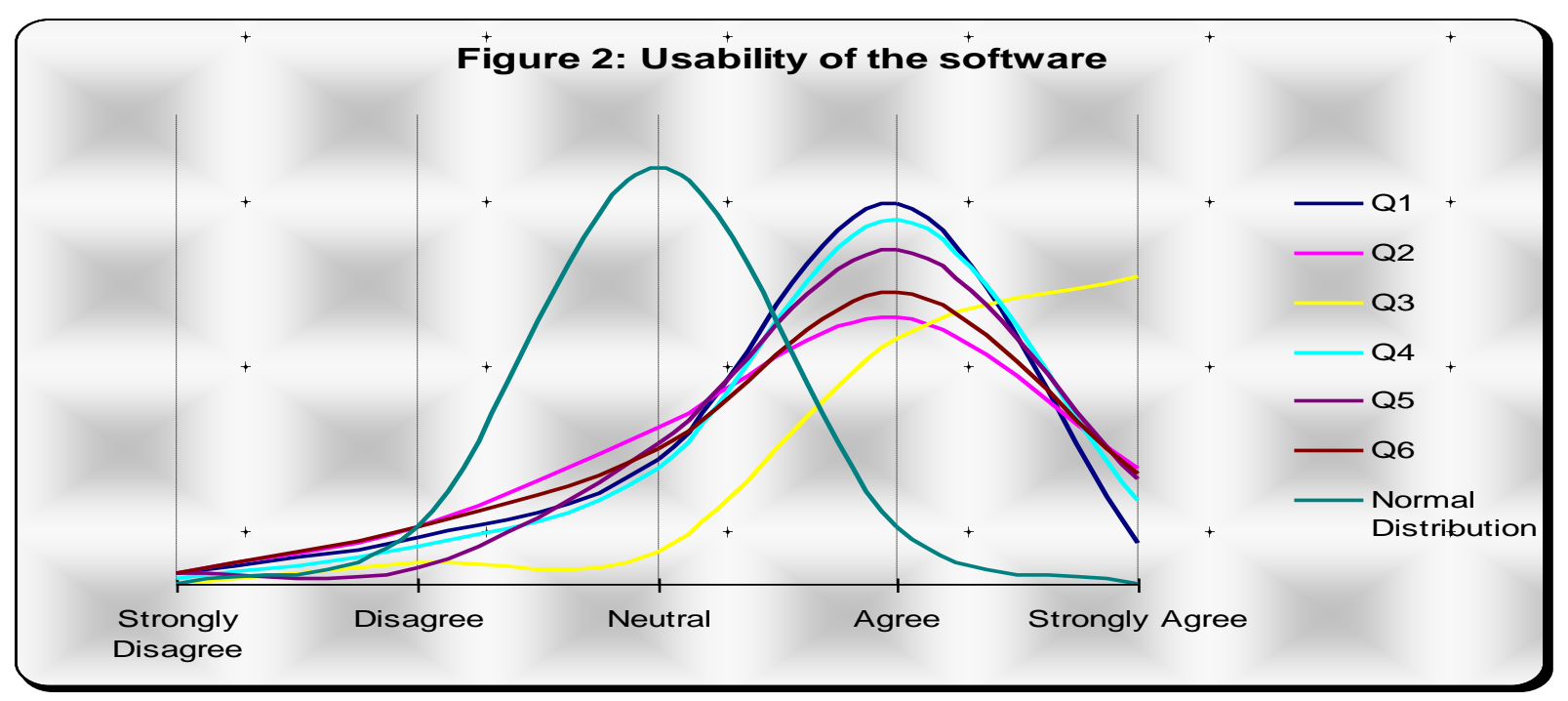

In Figure 2, as compared against the normal distribution, distributions of all the questions related to usability are positively skewed with heavy right tails.

In fact, for question 3, which is the use of case samples in helping students complete term projects, most of the students have either agreed or strongly agreed with the importance of case studies in providing guidance, thus resulting in S-shaped distribution.

\section{USEFULNESS OF GMPSO SOFTWARE}

Table 2 summarizes the average weighted mean, average standard deviation and coefficient of variation (in percentage) for the questions related to the usefulness of the software for the students.

\begin{tabular}{lccc}
\hline & \multicolumn{2}{c}{ Table 2: Usefulness of GMPSO software } \\
\hline & Average Weighted & Average & Average Weighted \\
& Mean & Weighted Variance & Standard Deviation \\
All Questions & 3.648168 & 1.170087 & 1.081705 \\
Without Outlier & 3.75 & 0.909408 & 0.953629 \\
\hline
\end{tabular}

In the survey conducted, 16 questions were asked from the students taking part in the class regarding the usefulness of the GMPSO software. In order to analyze the results regarding the usefulness of the software, the average mean over the sixteen questions is shown in left bar of Figure 3. The right bar reflects the average mean with the outlier removed. Figure 4 demonstrates the distribution.

In regards to usefulness of the software, the question related to the use of software individually and with the team was an outlier where over $40 \%$ of the students disagreed that the software should be used individually. This in turn resulted in bringing the average weighted mean down to 3.6. The coefficient of variation for the outlier was 
$106 \%$, thus showing high degree of volatility around the mean, therefore, depicting divergence in the opinion of the students.

If we discard the outlier, then the average weighted mean of the sample would be 3.8 and the coefficient of variation would decline from over $29 \%$ to $25 \%$. This implies that from the usefulness perspective, the majority of sample agreed that GMPSO software bolstered the productivity of the students.

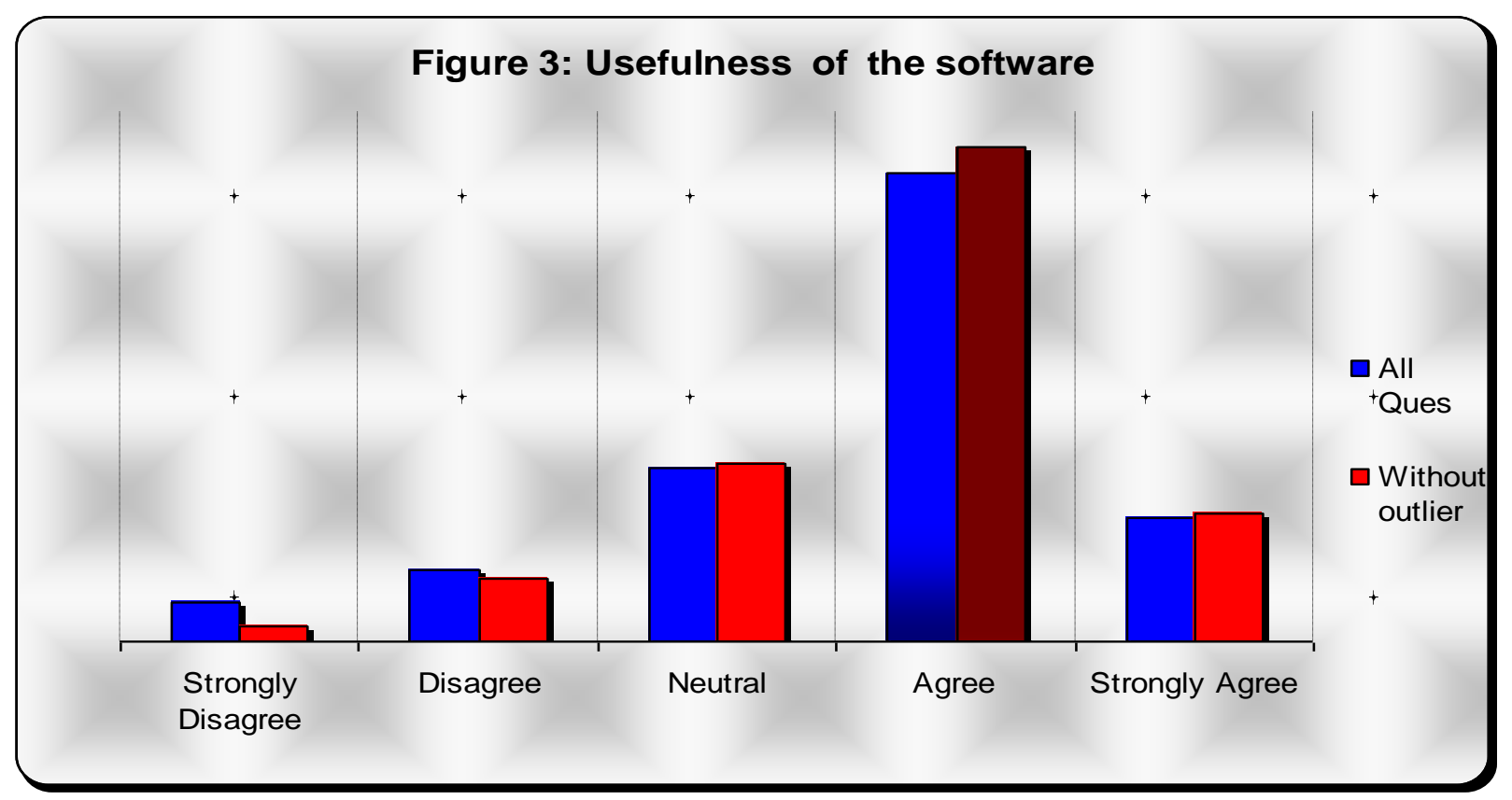

The question regarding whether the software could be put into better use if used in a team rather than in individual projects demonstrates the broader coverage of the software. On a positive note it could be concluded from the questionnaire that since the software is comprehensive, it can be put better use if used in group work rather than individual work, especially under stringent time constraints.

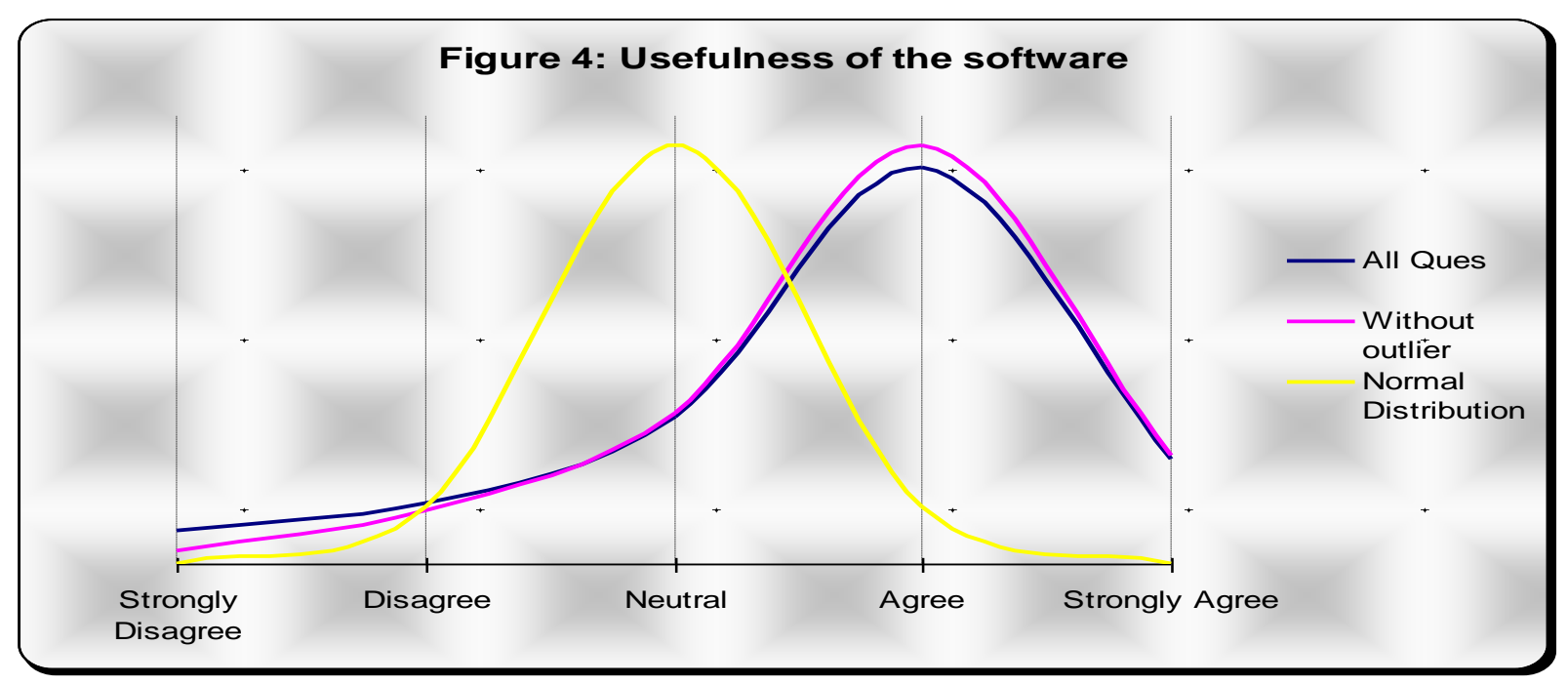




\section{GMPSO AS SKILL ENHANCEMENT SOFTWARE}

\begin{tabular}{cccc}
\hline & \multicolumn{3}{c}{ Table 3: Skills enhancement } \\
\hline Weighted Mean & Weighted Variance & Weighted Standard Deviation & Coefficient of Variation \\
3.793103 & 0.678755 & 0.823866 & 21.72011 \\
3.456897 & 1.199837 & 1.09537 & 31.68653 \\
3.706897 & 0.80113 & 0.895058 & 24.14576 \\
3.5 & 0.946046 & 0.972649 & 27.78998 \\
\hline
\end{tabular}

Another attribute of the software is the skill enhancement of the user; i.e., it not only aides the user in a paper but develops different skills of the user such as team working skills, research based skills, and critical thinking skills. Figure 5 and figure 6 demonstrate the development of different skills in an individual after having worked with the software.
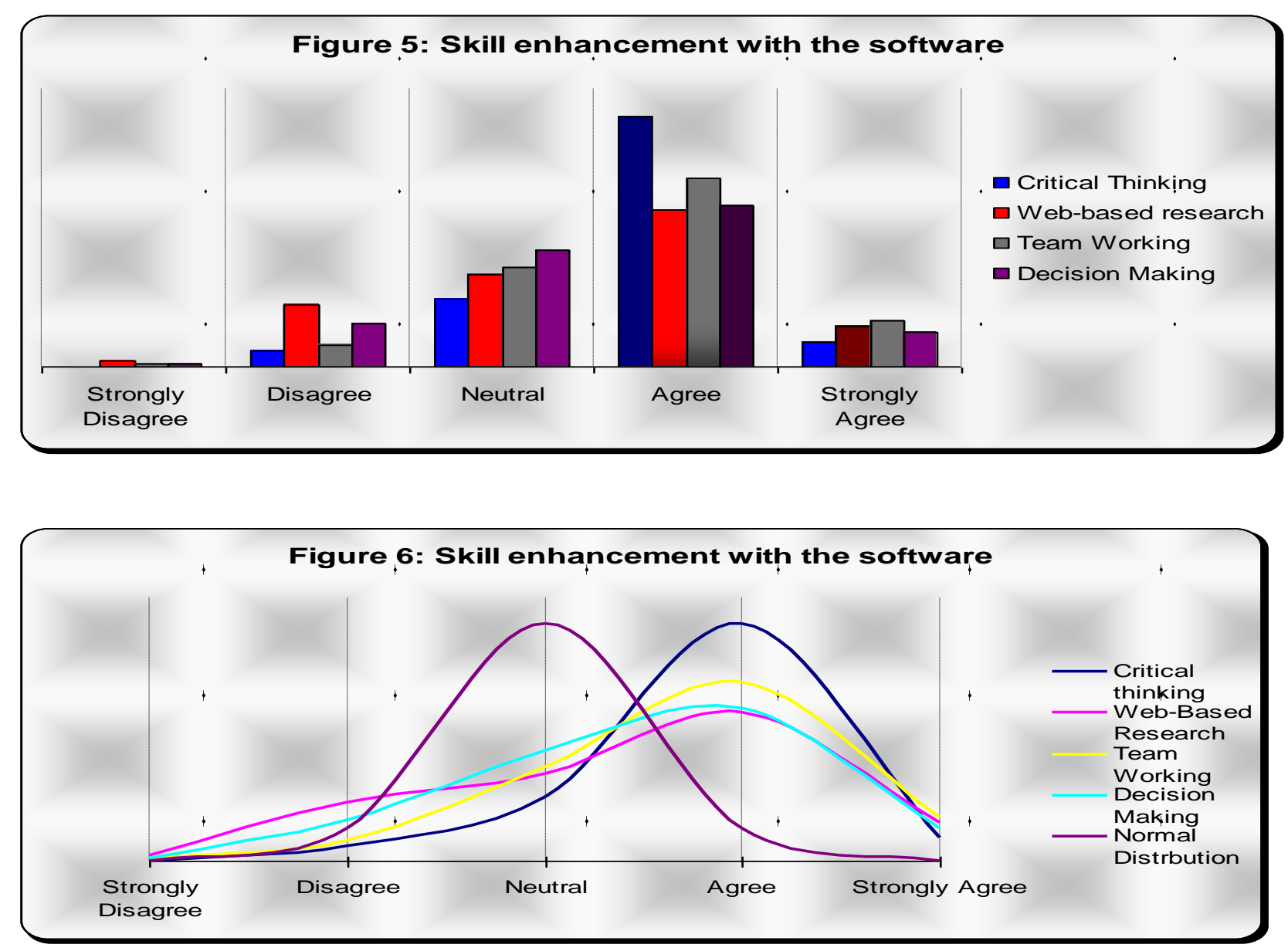

From Figure 6, it could be said that most of the students found the software helpful in honing their critical thinking skills but were skeptical in the ability of the software to improve their web based research ability. This is seen from the fairly platykurtic distribution of web-based research in Figure 6 . Nevertheless, it does reveal the usefulness of the software. 


\section{CONCLUSIONS}

In conclusion, the GMPSO software not only supports but also reinforces the theories and benefits of project-based and interactive learning. The survey results showed that international business projects based on the GMPSO software are an excellent way for students to enhance their understanding of international business and bridge the gap between theory and practice. More specifically, the findings indicate that use of the GMPSO software for the students' class project:

- $\quad$ Enhanced their understanding of international business concepts and practices.

- $\quad$ Enabled them to integrate and evaluate environmental factors (such cultural, economic, political and regulatory) affecting the decisions of firms pursuing global business opportunities.

- Allowed the integration and application of various business disciplines, in addition to international business, such as management, marketing and finance.

- $\quad$ Created an engaging environment that requires them to use critical thinking skills and enhance their decision making and team working skills.

- Improved their international business research skills and increase their awareness of useful online resources.

Further research is needed in the area of PBL and interactive learning to determine the benefits and pitfalls associated with web based software. It is recommended that instructors using the GMPSO software are also surveyed in order to determine their opinions and experiences with the software.

\section{ACKNOWLEDGEMENTS}

The authors would like to thank Instructor Richard Young for administering the questionnaire in his class and his valuable advise, Professor Fred Hoyt for his suggestions and feedback, Professor Harold Thiewes and graduate assistant Punyatib Cheema and Evangelos Kourkafas for their contribution in the analysis of the responses and formatting, and the instructors who use the software at different institutions for their helpful comments.

\section{REFERENCES}

1. Beck, John and Carstens, Adam (2005) Get Ready for the Gamer Generation, TechTrends: Linking Research and Practice to Improve Learning, Volume 49, Issue 3 (May/June), pp 22-25.

2. DeKanter, Nick (2005) Gaming Redefines Interactivity for Learning. TechTrends: Linking Research and Practice to Improve Learning, Volume 49, Issue 3 (May/June), pp 26-31.

3. Janavaras, Basil J. (2006) Global Market Potential System Online, http://www.globalmarket.com, Janavaras \& Associates International, Inc. (accessed 5 October 2006).

4. Jones, B. F., Rasmussen, C., and Moffitt, M. C. (1997) Real-Life Problem Solving: A Collaborative Approach to Interdisciplinary Learning, Washington, DC: American Psychological Association.

5. Kirkley, Jamie and Kirkley, Sonny (2005) Creating Next Generation Blended Learning Environments Using Mixed Reality, Video Games and Simulations. TechTrends: Linking Research and Practice to Improve Learning, Volume 49, Issue 3 (May/June), pp 42-53.

6. Shields, Elayne A (2005) A Guide to Project-Based Learning, McGraw-Hill On-Line Learning Center, http://www.mhhe.com/business/management/PBL/ (accessed 10 October 2006).

7. Thomas, John W. (2000) A Review of Research on Project-Based Learning, The Autodesk Foundation, http:www.autodesk.com/foundation. 


\section{APPENDIX A}

\section{GMPSO SURVEY QUSTIONNAIRE}

\section{Usability}

1. The instructions provided were clear and helpful in completing the project.

2. The web sites featured in the GMPSO were helpful in conducting research and completing the project

3. The case samples were helpful in completing the project.

4. The format of each phase was useful in completing the project.

5. The GMPSO seemed to be laid out logically.

6. The GMPSO should be completed individually (vs. groups).

7. The GMPSO based project should be completed:

- $\quad$ Entirely outside of class.

- $\quad$ During class time.

- In and outside of class.

8. The instructor's level of involvement was adequate.

\section{Usefulness}

9. The GMPSO enabled me to evaluate a company and the company's level of international involvement.

10. The GMPSO provided me with the opportunity to use business concepts and practices I acquired in other business courses.

11. The GMPSO enabled me to become familiar with a good number of useful web-based information sources.

12. The GMPSO increased my understanding of international business.

13. The GMPSO allowed me to determine a company's readiness to internationalize.

14. The GMPSO increased my understanding of different countries around the world.

15. The GMPSO enhanced my knowledge of cultural forces and its impact on business.

16. The GMPSO increased my understanding and appreciation of the impact of a country's economic and political system on business.

17. The GMPSO helped me identify high potential country markets for selected products or services.

18. The system allowed for an in-depth analysis of high market potential countries.

19. I was able to determine market potential for my product/service.

20. The GMPSO increased my understanding of the importance certain environmental factors have in selecting best markets for a given product/service.

21. The GMPSO helped better understand the role of international organizations (such as IMF, WTO) and their impact on business.

22. The GMPSO help me to better understand the impact of globalization forces on business.

23. I feel more businesses classes should try to incorporate projects like the GMPSO.

\section{Skills}

24. The GMPSO provided me with the opportunity to make use of my critical thinking skills.

25. The GMPSO improved my web-based research skills.

26. The GMPSO improved my team working skills.

27. The GMPSO improved my decision-making skills.

28. The GMPSO was more challenging and beneficial than other non-web based business projects I have done. 
NOTES 